\title{
Social huddling and physiological thermoregulation are related to melanism in the nocturnal barn owl
}

\author{
Amélie N. Dreiss $^{1,2} \cdot$ Robin Séchaud ${ }^{1} \cdot$ Paul Béziers $^{1} \cdot$ Nicolas Villain $^{1,3}$. \\ Michel Genoud ${ }^{1} \cdot$ Bettina Almasi $^{4} \cdot$ Lukas Jenni $^{4} \cdot$ Alexandre Roulin $^{1}$
}

Received: 8 May 2015 / Accepted: 19 October 2015 / Published online: 9 November 2015

(c) Springer-Verlag Berlin Heidelberg 2015

\begin{abstract}
Endothermic animals vary in their physiological ability to maintain a constant body temperature. Since melanin-based coloration is related to thermoregulation and energy homeostasis, we predict that dark and pale melanic individuals adopt different behaviours to regulate their body temperature. Young animals are particularly sensitive to a decrease in ambient temperature because their physiological system is not yet mature and growth may be traded-off against thermoregulation. To reduce energy loss, offspring huddle during periods of cold weather. We investigated in nestling barn owls (Tyto alba) whether body temperature, oxygen consumption and huddling were associated with melanin-based coloration. Isolated owlets displaying more black feather spots had a lower body temperature and consumed more oxygen than those with fewer black spots. This suggests that highly melanic individuals display a different thermoregulation strategy. This interpretation is also supported by the finding that, at relatively low ambient temperature, owlets displaying more black spots huddled more rapidly and more often than those displaying fewer spots. Assuming that spot number is associated with the ability to thermoregulate not only in Swiss barn
\end{abstract}

Communicated by Toni Laaksonen.

Amélie N. Dreiss

amelie.n.dreiss@gmail.com

1 Department of Ecology and Evolution, University of Lausanne, Lausanne, Switzerland

2 Institute of Ecology and Evolution, University of Bern, Bern, Switzerland

3 UMR 7179 CNRS, Museum National d'Histoire Naturelle, Brunoy, France

4 Swiss Ornithological Institute, Sempach, Switzerland owls but also in other Tytonidae, our results could explain geographic variation in the degree of melanism. Indeed, in the northern hemisphere, barn owls and allies are less spotted polewards than close to the equator, and in the northern American continent, barn owls are also less spotted in colder regions. If melanic spots themselves helped thermoregulation, we would have expected the opposite results. We therefore suggest that some melanogenic genes pleiotropically regulate thermoregulatory processes.

Keywords Huddling $\cdot$ Melanin $\cdot$ Metabolic rate $\cdot$ Oxygen consumption $\cdot$ Pleiotropy $\cdot$ Temperature $\cdot$ Thermoregulation

\section{Introduction}

The ability to maintain a relatively stable high body temperature independently of ambient temperature has allowed endothermic species to successfully colonise a wide range of habitats and live under different environmental conditions (Crompton et al. 1978; Irving and Krog 1954). On the other hand, endothermic homeothermy is a very costly strategy; endotherms spend energy at a rate about 10 times higher than ectotherms of the same size (Else and Hulbert 1981). Physiological processes of endotherms are optimised for a narrow range of body temperatures, and slight variations in body temperature (overcooling and overheating) can lead to a rapid impairment of the vital functions of an individual. The maintenance of a high and constant body temperature through thermoregulation is hence a crucial determinant of endotherms' fitness (Angilletta et al. 2010). As a consequence, spatial and temporal variations in ambient temperature induce individuals to modify behaviour and physiology in order to optimise body temperature and energy expenditure (Gilbert et al. 2010; Schmidt-Nielsen 
1997; Walsberg 1991). Analysing the different physiologi$\mathrm{cal}$ and behavioural strategies used in response to temperature variation is a key step to understand the evolution of many life-history traits.

Optimal thermoregulation can be achieved with alternative or concurrent strategies in endotherms. According to Angilletta et al. (2002), thermal physiology and thermoregulatory behaviour are likely to be co-adapted. Therefore, regulation of body temperature may be achieved equally through physiological mechanisms or specific behaviours. The individuals that are the least able to physiologically maintain a constant body temperature could thermoregulate, for instance, by selecting appropriate habitats (Jones and Boulding 1999; Muri et al. 2015). Another widespread behaviour to resist cold temperatures is social huddling, which consists of an active aggregation of individuals (Gilbert et al. 2010). This "social thermoregulation" is particularly beneficial in altricial young of many endotherms, which have to invest a substantial amount of energy to grow, and for which internal temperature varies to a larger extent than in homeothermic adults (Dunn 1975; Durant 2002; Forbes 2002). Huddling in young endotherms can reduce energy expenditure by $6-53 \%$, by decreasing convective heat loss and increasing radiative heat gain (Willis and Brigham 2007). Therefore, individuals that are less able to thermoregulate physiologically must display this social behaviour more frequently. While the determinants of social thermoregulation have been studied in detail (Gilbert et al. 2010), inter-individual variation in the propensity to huddle is not well understood (Hudson et al. 2011; Reyes-Meza et al. 2011).

In endotherms, individuals from the same population are not all equally able to thermoregulate and their body temperatures may vary from one individual to the other (Lichtenbelt et al. 2001, 2002). This raises the question of how this inter-individual variation is maintained. Genetic variation in body temperature has been reported in both domestic (Dikmen et al. 2012) and wild animals (Nespolo et al. 2003). Thermoregulatory ability can vary between conspecifics or populations, and it can be genetically correlated with other traits involved in thermoregulation, such as melanism (Parkash et al. 2010). In springbock (Antidorcas marsupialis), white individuals have a lower body temperature than dark conspecifics (Hetem et al. 2009) and studies in the pied flycatcher (Ficedula hypoleuca), scops owl (Otus asio), tawny owl (Strix aluco) and screech owl (Megascops asio) have shown that individuals displaying different melanin-based colorations cope differently with warm and cold temperatures (Galeotti et al. 2009; Järvistö et al. 2015; Karell et al. 2011; Mosher and Henny 1976; Roulin et al. 2005; Sirkiä et al. 2010, 2013). This suggests that melanistic traits may co-evolve with resistance to variations in ambient temperature, raising the possibility that differently coloured individuals could have a different thermal physiology and adopt different thermoregulation strategies. Several non-mutually exclusive proximate mechanisms may account for an association between melanin-based coloration and body temperature. First, black colorations absorb more solar radiation under most environmental conditions (Clusella-Trullas et al. 2008; Heppner 1970; Walsberg et al. 1978), implying that darker individuals may have a higher body temperature (Hegna et al. 2013; Hetem et al. 2009). Second, dark- and palecoloured individuals exploit different habitats where ambient temperatures differ (Karpestam et al. 2012; Kearney et al. 2009; Tanaka 2007). Even if dark and pale colorations are adapted to specific habitats for other reasons than thermoregulation (such as predation pressure or resistance to stress; Caro 2013; Kittilsen et al. 2009), systematic differences in ambient temperatures between habitats may select for different behavioural and/or physiological thermoregulatory traits that become genetically correlated with coloration. Finally, genes involved in melanogenesis play a role in thermoregulation and other associated physiological traits, such as metabolic rate, food consumption and physical activity (Ducrest et al. 2008), generating genetic correlations between colour and body temperature. Based on all these non-mutually exclusive reasons, we predict a covariation between the degree of melanin-based coloration, body temperature and behavioural thermoregulation.

In the present study, we investigated whether body temperature, oxygen consumption and behavioural thermoregulation through huddling are related to melanin-based coloration in barn owl (Tyto alba) nestlings. This species shows a pronounced variation in coloration which covaries with a large range of physiological processes, behaviour and life-history traits (Roulin and Ducrest 2011). We expect that inter-individual variations in body temperature, oxygen consumption and behavioural thermoregulation should be correlated and that thermoregulation strategy should covary with melanism, first because differently coloured barn owls exploit alternative local habitats (Dreiss et al. 2012). In the North American continent, plumage traits covary with climate: owls from colder regions are darker reddish and display larger (but fewer) black spots (Roulin and Randin 2015). Second, we have already shown that mothers displaying larger black feather spots spend more time brooding their progeny (Almasi et al. 2013). Barn owl eumelanic spots are scattered and only 1-2 mm wide (see Ducrest et al. 2008), and hence should have a low capacity of thermoregulating, particularly in a nocturnal species. The melanocortins involved in their synthesis could, however, influence energy homeostasis by reducing body temperature and increasing oxygen consumption (Challis et al. 2004; Ducrest et al. 2008; Sinha et al. 2004), although melanocortin effects are sometimes contradictory 
(Lute et al. 2014). We hence predict that darker eumelanic nestlings should have a higher metabolic rate and a lower body temperature, and should hence huddle more with their siblings to warm up, which is opposite to the predictions we would have proposed if black spots themselves played a role in absorbing warmth.

We performed three studies using independent samples of thermo-independent barn owl nestlings. In 2011, we measured cloacal temperatures in barn owls in their natural environment and analysed their correlation with three melanic traits (reddish plumage coloration, black spot diameter and number). Because cloacal temperatures were higher in highly spotted nestlings, we predicted that their oxygen consumption would be higher and that they would aggregate with their siblings more often and more rapidly than less spotted owlets. In 2014, we exposed nestlings to three temperature treatments in the laboratory and compared their oxygen consumption at rest (resting metabolic rate, RMR), which reflects the minimum amount of energy necessary for the basic metabolic functions. Additionally, we verified that body temperature was correlated with black spot number as in 2011. In 2012, we brought freeliving nestlings to the laboratory and placed them in nestboxes similar to those occupied in the field to record their huddling behaviour under standardised conditions.

\section{Materials and methods}

\section{Study population}

The study was performed in Switzerland $\left(46^{\circ} 4^{\prime} \mathrm{N}, 6^{\circ} 5^{\prime} \mathrm{E}\right)$ on a population of wild barn owls breeding in nest-boxes located in barns. Females start incubating their eggs as soon as the first egg has been laid and, since eggs hatch every 2.5 days, the brood has a staggered range of nestling sizes. Around 2 weeks after the last offspring hatches, the mother starts sleeping outside the nest-box and is hence no longer involved in nestling thermoregulation. Parents come back only at night to bring a single small mammal per visit. Nestling age was estimated shortly after hatching by measuring the length of the left flattened wing from the bird's wrist to the tip of the longest primary (Roulin 2004a). Nestling sex was determined using molecular markers (Py et al. 2006).

\section{Body temperature}

From 20 May to 29 August 2011, we recorded ambient temperatures inside the barns where nest-boxes were placed (mean \pm SE: $22.1{ }^{\circ} \mathrm{C} \pm 0.7$; range $13.5-33.3{ }^{\circ} \mathrm{C}$ ) and body temperature of 92 nestlings ( 34 males and 58 females) from 31 broods (mean $\pm \mathrm{SE}: 38.1{ }^{\circ} \mathrm{C} \pm 0.1$; range
31.0-40.8 $\left.{ }^{\circ} \mathrm{C}\right)$. Nestlings were measured once between the ages of 11 and 35 days (mean \pm SE: $20 \pm 0.5$ ). The sampling time of measurements was $26 \pm 1 \mathrm{~min}$ after the arrival of the observer to the nest (range 23-29 min), and all measurements were performed during the second part of the day from 1345 to 1845 hours. The body temperature was estimated by introducing $10 \mathrm{~mm}$ of the probe into the cloaca using a Fluke $52 \mathrm{~K} / \mathrm{J}$ thermometer. Once the temperature was stable, we waited $10 \mathrm{~s}$ before recording the temperature. If the nestlings defecated during this process, temperature was not recorded.

\section{Oxygen consumption}

Between 3 June and 9 September 2014, we brought 33 nestlings from 18 broods (35-47 days old, mean \pm SE: $41.1 \pm 0.2)$ to the laboratory. We recorded body temperature of all nest-mates immediately after opening the nest-box (49 males and 31 females aged 33-47 days, $40.9 \pm 0.4$ ), using the same method as above. We used the mean cloacal temperature of 6 measures performed at regular intervals from 5 to $60 \mathrm{~min}$ after capture. At 1900 hours, nestlings brought to the laboratory were placed into plexiglas boxes (see below), where they spent the night to get accustomed to the experimental conditions. The nestlings were post-absorptive at the time when measurements were done, as they were neither fed before nor during the experiment. We performed the experiment during the day, when the nestlings rest. Metabolic measurements started at 0600 and finished at 1800 hours on the same day, a period during which nestlings were consecutively exposed to three different temperature treatments: 14,24 and $30{ }^{\circ} \mathrm{C}$. The thermoneutral zone (TNZ) of adult barn owl ranges between 23 and $32{ }^{\circ} \mathrm{C}$ (Edwards 1987; Thouzeau et al. 1999). We chose 24 and $30{ }^{\circ} \mathrm{C}$, close to the lower and upper limits of the TNZ of adult barn owls, as temperatures at which nestlings should spend little energy to control their body temperature. The lowest experimental temperature treatment, $14{ }^{\circ} \mathrm{C}$, lies below the TNZ, but is a common temperature in the study area. All metabolic rates measured (even at thermoneutral temperatures) are hereby referred to as resting metabolic rates (RMR) rather than basal metabolic rates (BMR), as they were obtained on developing nestlings rather than adults and hence do not meet all requirements for the BMR (McNab 1997). Each nestling was assigned one of two different protocols, the first one beginning at $14{ }^{\circ} \mathrm{C}$ and ending at $30{ }^{\circ} \mathrm{C}$ and the second one starting at $30{ }^{\circ} \mathrm{C}$ and finishing at $14{ }^{\circ} \mathrm{C}$, both having $24^{\circ} \mathrm{C}$ as the second treatment temperature. Nestlings spent $3 \mathrm{~h}$ under each temperature treatment. To soften transitions between successive temperature treatments, nestlings spent $1 \mathrm{~h}$ at an intermediate temperature $\left(19{ }^{\circ} \mathrm{C}\right.$ between treatments 14 and $24^{\circ} \mathrm{C}$, and $27^{\circ} \mathrm{C}$ between treatments 24 and $30^{\circ} \mathrm{C}$ ). 


\section{Metabolic measurements}

Two nestlings in individual plexiglas boxes $\left(21 \times 21 \times 26 \mathrm{~cm}^{3}\right.$, containing a slip mat covered with sawdust) were measured in parallel in the same climatic chamber (Sanyo MLR-350 $\mathrm{H}$; Sanyo Electric, Japan). The metabolic rate was measured as oxygen consumption $\left(\mathrm{VO}_{2}\right)$ with an open flow respirometry system (Sable Systems International, Las Vegas, USA). Mass Flow Systems (MFS) continuously pumped air out of each two boxes and the climatic chamber at a rate of $1 \mathrm{~L} / \mathrm{min}$. A subsample of air $(500 \mathrm{~mL} / \mathrm{min})$ was pumped from one of these three air lines, following a fixed computer-driven schedule (Expedata software) and using a Multiplexer (MUX) to automatically switch between the different air lines. The subsampler (Subsampler SS4) pushed the air through the analyzers of water vapour (RH-300), carbon dioxide analyzer (CA-10) and finally oxygen concentration (FC-10).

Each 3-h temperature treatment was divided into a first hour during which no measurements were made, followed by two 1-h cycles of measurements. During a cycle, the oxygen consumption and carbon dioxide production of each nestling were recorded 4 times during 4 min (one sample per second). Baselines lasting 4 min were obtained in the climatic chamber, at the beginning, in the middle and at the end of each cycle, and allowed to correct for baseline drift. Oxygen consumption was calculated using the equation.

$\mathrm{VO}_{2}=\mathrm{FR} \times \frac{\left(\mathrm{F}_{\mathrm{i}} \mathrm{O}_{2}-\mathrm{F}_{\mathrm{e}} \mathrm{O}_{2}\right)-\mathrm{F}_{\mathrm{i}} \mathrm{O}_{2} \times\left(\mathrm{F}_{\mathrm{e}} \mathrm{CO}_{2}-\mathrm{F}_{\mathrm{i}} \mathrm{CO}_{2}\right)}{1-\mathrm{F}_{\mathrm{i}} \mathrm{O}_{2}}$,

where $\mathrm{FR}$ is the flow rate $(\mathrm{mL} / \mathrm{min}), \mathrm{F}_{\mathrm{i}} \mathrm{O}_{2}$ and $\mathrm{F}_{\mathrm{e}} \mathrm{O}_{2}$ are the incurrent (baseline) and the excurrent (box) fractional concentration of oxygen, respectively, $\mathrm{F}_{\mathrm{i}} \mathrm{CO}_{2}$ and $\mathrm{F}_{\mathrm{e}} \mathrm{CO}_{2}$ are the incurrent (baseline) and the excurrent (box) fractional concentration of carbon dioxide, respectively. All parameters of the above equation were corrected for water vapour pressure and hence $\mathrm{VO}_{2}$ corresponds to standard temperature and pressure desaturated (STPD) conditions.

We extracted 8 mean values of $\mathrm{VO}_{2}$ and their associated standard deviation, per individual per treatment, by averaging the last 120 samples (i.e. $2 \mathrm{~min}$ ) of each 4-min sequence (there were 2 cycles of 4 such sequences per treatment). We excluded the sequences associated with a particularly high standard deviation (highest $25 \%$, i.e. above $11 \mathrm{~mL} / \mathrm{h}$ ), reflecting an unstable $\mathrm{VO}_{2}$, possibly due to slight movements of the chicks. Final oxygen consumption values, per individual per treatment, were obtained by averaging the two lowest mean values of $\mathrm{VO}_{2}$.

\section{Social thermoregulation}

From 27 May to 27 August 2012, we brought 116 nestlings from 30 broods ( 54 males, 61 females, 1 of unknown gender; age range 16-39 days) into the laboratory for three nights. Nestlings were placed in nest-boxes similar to the ones in which they were reared in the field $(62 \times 56$ $\times 37 \mathrm{~cm}^{3}$ ), but twice as high so as to include an infra-red camera in the ceiling to record nestling positions (TVCCD150SET; Monacor International, Bremen, Germany). Nestboxes were equipped with a pipe $(10 \mathrm{~cm}$ in diameter and $20 \mathrm{~cm}$ long) connected to the outside to allow exchange of air and provide dim natural light. To increase internal lighting during the daylight hours, we attached a lamp (LEDs, $1 \mathrm{~W})$ to the ceiling, which automatically switched on at sunrise and switched off at sunset. The lamp created light conditions similar to those experienced in the natural nests during daylight hours. Each individual was recorded during one or two sessions of $23 \mathrm{~h}$, from 1400 to 1300 hours the next day, with either an older (junior treatment) or a younger sibling (senior treatment), the order being randomly chosen. Forty-one nestlings experienced the "junior" and "senior" treatments, 38 only the "junior" treatment and 37 only the "senior" treatment. During each 23-h treatment, boxes were closed and individuals were left undisturbed. At the beginning of each treatment, we placed $240 \mathrm{~g}$ of dead mice (ca. 8 mice of $30 \mathrm{~g}$ ) in a corridor located in the middle of the box, one extremity against the long side of the box and the other extremity opening on the centre of the box. Siblings were then placed on either side of the corridor, each one in a corner of the box, so that they did not see each other. We recorded ambient temperatures at midnight using a logger placed on the ceiling of the boxes (range 18.5-31.5'; Cibutton DS1921G; Maxim Integrated, San Jose, CA, USA).

During each time interval of $1 \mathrm{~min}$, nestlings were considered together when touching each other at least during $45 \mathrm{~s}$. Therefore, our measure of huddling behaviour during a 23-h session is given by the number of minutes during which the two siblings were touching each other during at least 45 out of $60 \mathrm{~s}$. Because nestlings displacing more around the nest-box are likely to huddle less, we also controlled for individual activity. Nestlings were considered 'active' at a given minute if they moved during at least $45 \mathrm{~s}$. We recorded nestling behaviour using RealPlayer software (8 images/s, v.15.0.6.14, Helix Powered; RealNetworks, USA).

\section{Plumage traits}

Barn owl ventral body side varies from white to dark reddish, a pheomelanin trait (Roulin et al. 2008), and from immaculate to highly spotted with black spots, a trait related to individual eumelanin production (Roulin et al. 2013). Pheomelanin-based plumage colour was assessed on the breast, belly, one flank and the underside of one wing by visual comparison with eight colour chips, ranging from 
-VIII for white to -I for dark reddish-brown, a method previously validated by Dreiss and Roulin (2010). The number and diameter (measured to the nearest $0.1 \mathrm{~mm}$ ) of eumelanin-based black spots, located at the tip of ventral feathers, were recorded on the breast using the methods described in previous studies (Roulin 2004b). Since nestling plumage was not fully developed at the time of the experiments, we assessed pheomelanin-based colour at the nest shortly before fledging.

\section{Statistical analyses}

For the analysis of social thermoregulation, the time span between the start of the experiment (1400 hours) and the first huddling between the two siblings, as well as the percentage of time the two siblings spent together in close contact, were normalised with logarithm and arcsine transformations, respectively. To analyse the relationship between the propensity to huddle and plumage traits, we calculated mean values of sibling pairs. Oxygen consumption was normalised with a Box-Cox transformation.

When the interaction between the terms temperature and number of black spots was significant, we split the sample in equal parts [below and above the median temperature or spot number (45 in 2014 and 50 in 2012)]. We ran post hoc analyses with half the sample, in order to further analyse and understand the interaction. When this interaction was not significant, we removed this term from the model. A small number of observations of plumage traits and body temperature were missed out or some individuals, which explain slight variations in sample size among tests. Statistical analyses were performed with SAS v.9.1 (SAS Institute, Cary, NC, USA). Means are indicated \pm standard error.

\section{Ethical note}

Bringing nestlings to the laboratory for three nights did not affect nestling growth rate and survival (Dreiss et al. 2013). We left one or two nestlings in their natural nest to ensure that parents did not abandon their brood, an event that never occurred. Parents brought the same amount of prey after we reduced their brood for a few days (Roulin et al. 2000), implying that the nestlings that remained in the nest were well fed and that once we brought back nestlings to their nest, they were fed at a similar rate as before their stay in the laboratory. The experiments were approved by the veterinary services of canton de Vaud (Form No. 2109.1). In the laboratory, nestlings were not physiologically stressed, as measured by baseline corticosterone levels (Dreiss et al. 2010).

\section{Results}

\section{Body temperature}

Nestlings displaying more black spots showed a lower body temperature than less spotted nestlings in 2011 (Table 1a; Fig. 1), which was confirmed in 2014 (Table 1b; Fig. 1). Body temperature increased with ambient temperature (Table 1; Fig. 2) and was significantly higher in older nestlings (Table 1).

\section{Oxygen consumption}

Oxygen consumption was related to the interaction between temperature treatment and nestling spot number (Table 2; Fig. 3). Post hoc analyses showed that at $24{ }^{\circ} \mathrm{C}$

Table 1 Body temperature in relation to melanin-based plumage traits (number and size of black feather spots and reddish plumage coloration) in nestling barn owls (Tyto alba)

\begin{tabular}{|c|c|c|c|c|c|c|c|c|}
\hline \multirow[t]{2}{*}{ Effect } & \multicolumn{4}{|l|}{ (a) 2011} & \multicolumn{4}{|l|}{ (b) 2014} \\
\hline & Estimate $\pm \mathrm{SE}$ & $\mathrm{CI}$ & $F$ & $P$ & Estimate $\pm \mathrm{SE}$ & $\mathrm{CI}$ & $F$ & $P$ \\
\hline Ambient temperature & $0.22 \pm 0.03$ & $0.16-0.28$ & 51.79 & $<0.0001$ & $0.20 \pm 0.04$ & $0.11-0.28$ & 20.89 & $<0.0001$ \\
\hline Date & $-0.005 \pm 0.005$ & -0.015 to -0.004 & 1.26 & 0.27 & $0.007 \pm 0.003$ & $\mathbf{0 . 0 0 1}$ to $-\mathbf{0 . 0 1 3}$ & 4.10 & 0.048 \\
\hline Time of the day (h) & $-0.02 \pm 0.05$ & -0.11 to 0.07 & 0.23 & 0.63 & $0.68 \pm 0.19$ & $0.3-1.05$ & 13.19 & 0.0007 \\
\hline Number of spots & $-0.014 \pm 0.004$ & $-\mathbf{0 . 0 2 3}$ to $-\mathbf{0 . 0 0 4}$ & 8.24 & 0.006 & $-0.015 \pm 0.006$ & $-\mathbf{0 . 0 2 4}$ to $-\mathbf{0 . 0 0 4}$ & 7.01 & 0.011 \\
\hline Spot diameter & $0.041 \pm 0.037$ & -0.033 to 0.115 & 1.23 & 0.27 & $0.077 \pm 0.050$ & -0.024 to 0.179 & 2.34 & 0.13 \\
\hline Reddish colour & $-0.076 \pm 0.078$ & -0.23 to 0.08 & 0.93 & 0.34 & $0.028 \pm 0.081$ & -0.13 to 0.19 & 0.12 & 0.73 \\
\hline Nestling age & $0.19 \pm 0.023$ & $0.15-0.24$ & 68.92 & $<0.0001$ & $\mathbf{0 . 0 7} \pm \mathbf{0 . 0 3}$ & $0.01-0.13$ & 6.19 & 0.016 \\
\hline Nestling sex (M vs. F) & $-0.14 \pm 0.23$ & -0.61 to 0.33 & 0.36 & 0.55 & $-0.26 \pm 0.23$ & -0.74 to 0.20 & 1.34 & 0.25 \\
\hline
\end{tabular}

Results of linear mixed models with brood identity set as random factor for (a) 92 nestlings from 31 broods in $2011, d f=1.64$ and (b) 80 nestlings from 16 broods in $2014, d f=1.48$

Significant values in bold

CI Confidence interval 
(a)

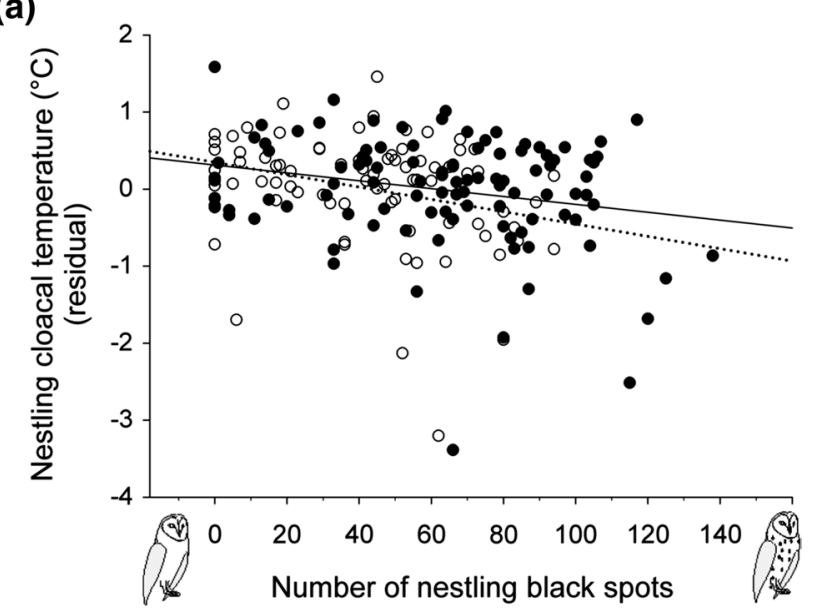

(b)

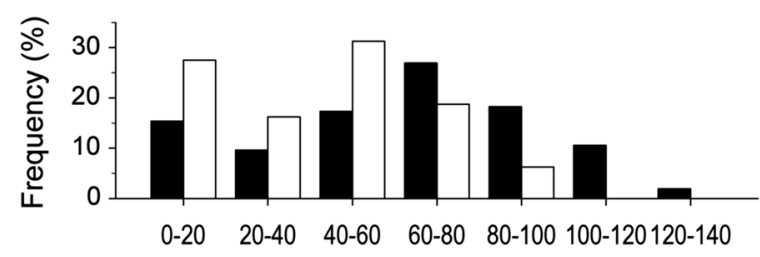

Fig. 1 a Body temperature $\left({ }^{\circ} \mathrm{C}\right)$ of nestling barn owls (Tyto alba) as a function of number of black feather spots in 2011 (black) and 2014 (white). Residuals values of the models Table 1. b Frequency distribution of number of black feather spots in nestling barn owls measured in 2011 (black) and 2014 (white) (a)

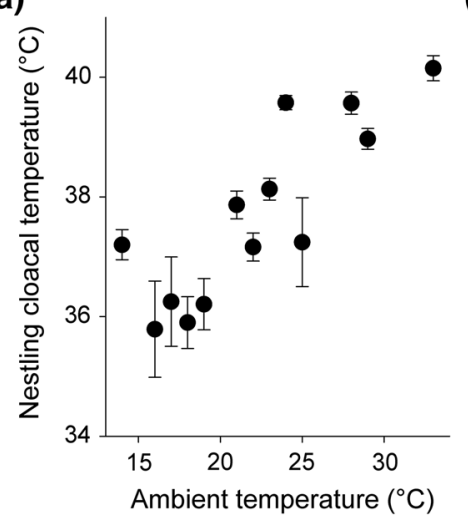

(b)

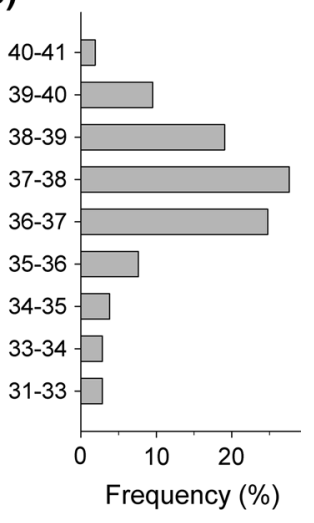

Fig. 2 Body temperature $(\mathbf{a})\left({ }^{\circ} \mathrm{C} \pm \mathrm{SE}\right)$ and its distribution (b) as a function of ambient temperature $\left({ }^{\circ} \mathrm{C}\right)$ in nestling barn owls measured in 2011

oxygen consumption increased significantly with spot number $\left(F_{1,17}=12.67, P=0.0024\right.$, estimate for spot number: $0.6 \pm 0.2$ ), while it was not the case with the other temperature treatments $\left(14^{\circ} \mathrm{C}: F_{1,17}=1.41, P=0.25\right.$, estimate: $0.3 \pm 0.3 ; 30^{\circ} \mathrm{C}: F_{1,16}=0.51, P=0.48,-0.1 \pm 0.2$, Fig. 3).
Table 2 Oxygen consumption in barn owl nestlings

\begin{tabular}{lll}
\hline Effect & $F$ & $P$ \\
\hline Temperature treatment $(T)$ & 5.80 & 0.005 \\
Date & 2.26 & 0.14 \\
Number of spots & 2.81 & 0.10 \\
Nestling age & 0.30 & 0.59 \\
Nestling sex & 0.42 & 0.52 \\
$T \times$ number of spots & 3.93 & 0.024 \\
\hline
\end{tabular}

Results of a linear mixed model with experimental box and individual identity nested in brood identity set as random factors. Data are from $2014(d f=66)$

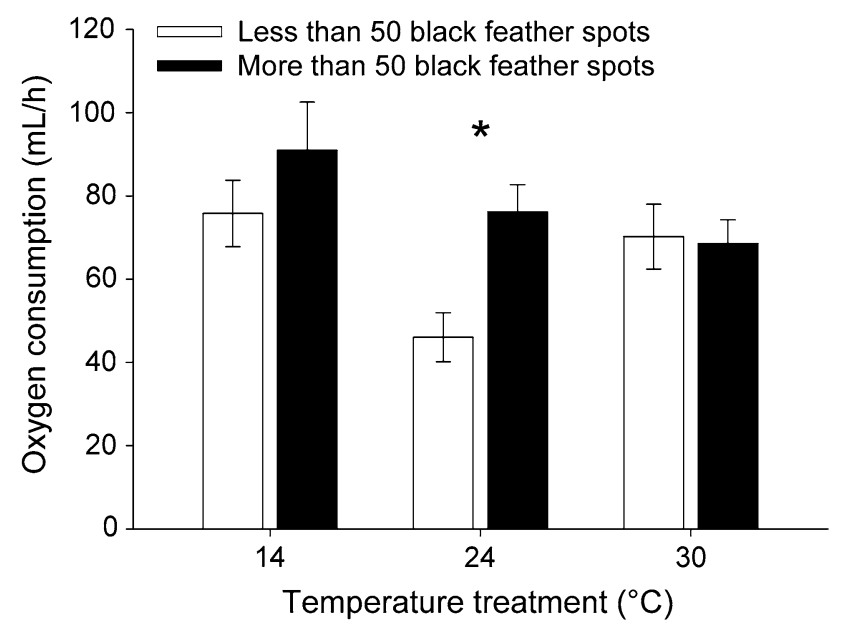

Fig. 3 Oxygen consumption $(\mathrm{mL} / \mathrm{h})$ in highly spotted nestling barn owls ( $>50$ feather spots, the median) and less spotted owlets $(<50$ feather spots) at three different experimental temperatures measured in 2014

\section{Social thermoregulation}

Nestlings spent on average $78 \pm 1 \%$ of their time huddling (range 36-97\%). The total amount of time a pair of siblings spent together was related to the interaction between mean sibling spot number and ambient temperature (Table 3). In post hoc analyses, highly spotted pairs (with more than 45 black spots, the median) spent more time together at low than at high ambient temperatures (similar model as in Table 3 with highly spotted pairs; $F_{1,7}=15.69$, $P=0.004$, estimate for temperature: $-0.04 \pm 0.01$; Fig. 4). Instead, for pairs of nestlings displaying fewer spots, the time spent together was not related to ambient temperature $\left(F_{1,4}=0.56, P=0.49\right.$, estimate for temperature: $-0.01 \pm 0.02$; Fig. 4 ).

On average, nestlings reunited $48 \pm 8$ min after we placed them at opposite sides of a nest-box (range $1 \mathrm{~min}$ to $9 \mathrm{~h} 30 \mathrm{~min}$ ). The identity of the individual which initiated 
Table 3 Percentage of time two barn owl siblings spent huddling

\begin{tabular}{lrl}
\hline Effect & \multicolumn{1}{l}{} & $P$ \\
\hline Ambient temperature $(T)$ & 2.14 & 0.17 \\
Date & 1.55 & 0.24 \\
Mean nestling activity & 16.75 & 0.001 \\
Mean number of spots & 6.49 & 0.024 \\
Mean nestling age & 8.43 & 0.012 \\
$T \times$ mean number of spots & 6.20 & 0.027 \\
\hline
\end{tabular}

Results of a linear mixed model with experimental day (nestlings were recorded during 1 or 2 days, always with a different sibling) and individual identity nested in brood identity set as random factors. The analysis is based on 81 observation sessions of $23 \mathrm{~h}$ with 89 different nestlings from 22 broods in $2012(d f=13)$. For each pair of siblings, we calculated mean values

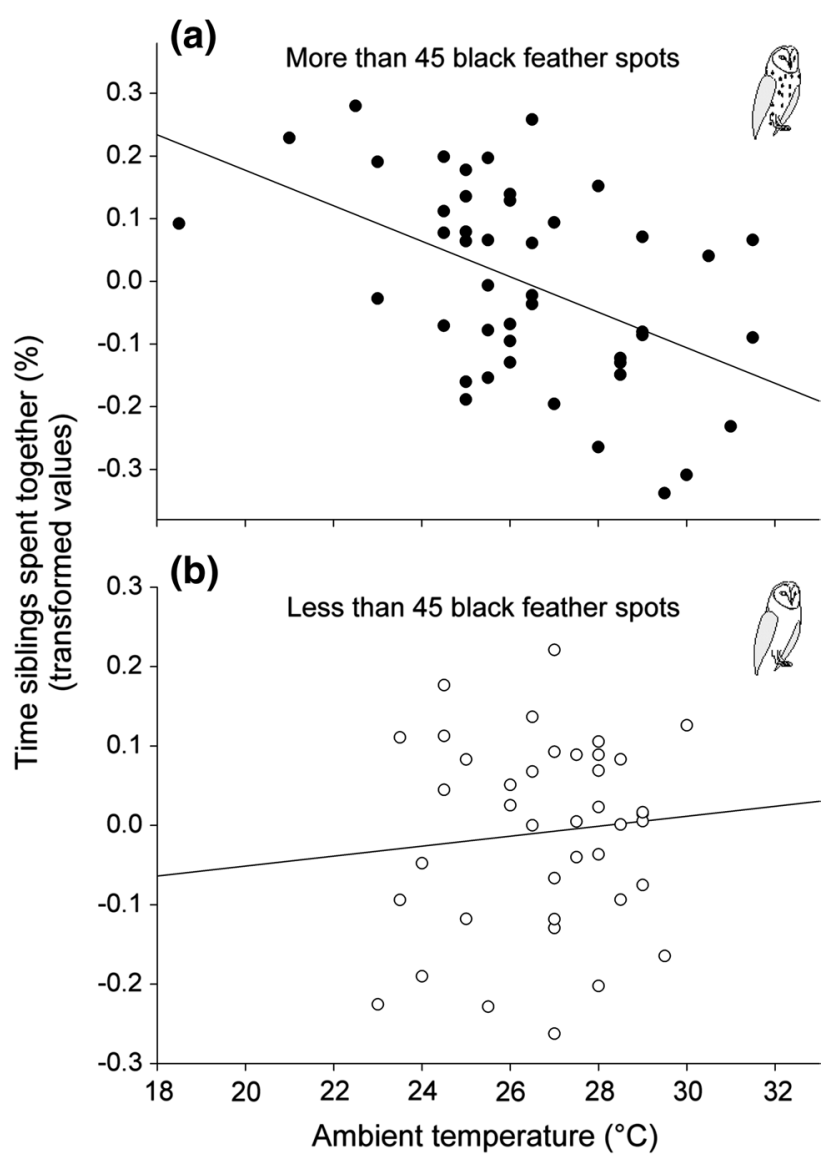

Fig. 4 Percentage of time barn owl siblings spent together during the $23 \mathrm{~h}$ experimental sessions in relation to ambient temperature in highly spotted nestling barn owls ( $>45$ feather spots on average, the median) and less spotted ones ( $<45$ feather spots). Data are from 2012

the first contact with its sibling was predicted by the statistical interaction between ambient temperature and plumage spot number (Table 4$)$. At low temperatures $\left(<26{ }^{\circ} \mathrm{C}\right.$, i.e., the median of all recorded ambient temperatures),
Table 4 Probability of initiating the first physical contact in pairs of barn owl siblings in relation to ambient temperature and plumage traits

\begin{tabular}{lll}
\hline Effect & $F$ & $P$ \\
\hline Ambient temperature $(T)$ & 5.26 & 0.026 \\
Date & 0.01 & 0.91 \\
Nestling physical activity & 0.86 & 0.36 \\
Number of spots & 6.88 & 0.011 \\
Nestling age & 0.08 & 0.77 \\
Nestling sex & 0.07 & 0.80 \\
$T \times$ number of spots & 6.76 & 0.012 \\
\hline
\end{tabular}

Results of a GLMM with binomial distribution including nestling pair, brood identity and experimental day set as random factors. Data are from $2012(d f=55)$

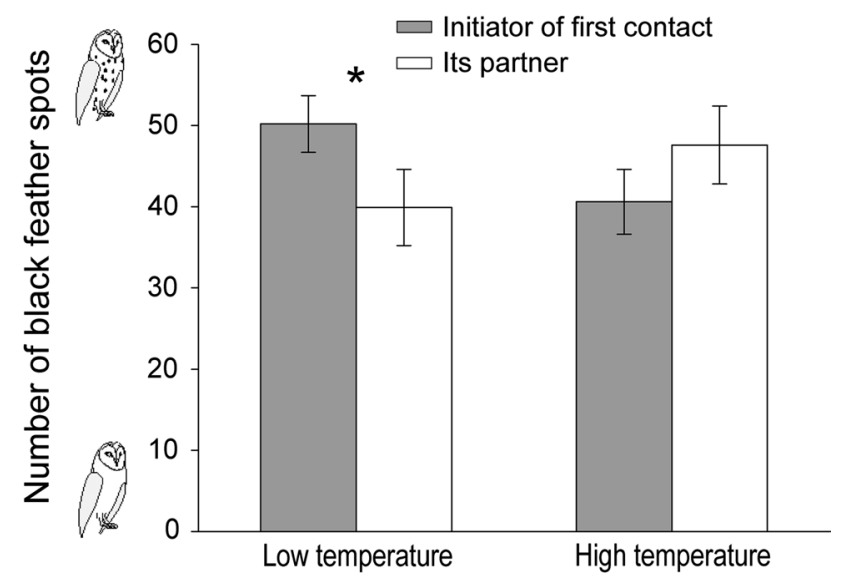

Fig. 5 Number of black spots displayed by the nestling that initiated the first physical contact and by its partner at low $\left(<22{ }^{\circ} \mathrm{C}\right.$, the median) and high ambient temperature $\left(>22{ }^{\circ} \mathrm{C}\right)$. The "initiator" is the first nestling to approach its sibling and touch it, after the sibling pair was placed in the experimental nest-box. Data are from 2012

the nestling that initiated the first contact displayed on average more black spots than its sibling (paired $t$ test: $t_{(47)}=2.04, P=0.046$, Fig. 5), a finding that did not apply at higher temperatures $\left(t_{(28)}=-1.36, P=0.18\right)$. Furthermore, the very first contact occurred sooner when its initiator displayed more eumelanic spots (Table 5; estimate: $-0.015 \pm 0.004$; Fig. 6). Siblings huddled faster at the end of the breeding season than earlier (Table 5; estimates for "date": $-0.018 \pm 0.004)$.

\section{Discussion}

Nestling barn owls displaying more black spots on the tip of their ventral feathers had a lower body temperature (Fig. 1) and higher resting metabolic rate at $24{ }^{\circ} \mathrm{C}$ (Fig. 3) than less eumelanic ones. Nestlings displaying more black 
Table 5 Timing of the first physical contact in pairs of barn owl siblings

\begin{tabular}{lcl}
\hline Effect & $F$ & $P$ \\
\hline Ambient temperature $(T)$ & 0.01 & 0.99 \\
Date & 11.64 & 0.006 \\
Nestling activity & 3.97 & 0.07 \\
Number of spots & 5.72 & 0.035 \\
Nestling age & 0.54 & 0.48 \\
Nestling sex & 0.03 & 0.86 \\
$T \times$ number of spots & 2.07 & 0.18 \\
\hline
\end{tabular}

Results of a linear mixed model with experimental day and individual identity nested in brood identity set as random factors. Data are from $2012(d f=11)$

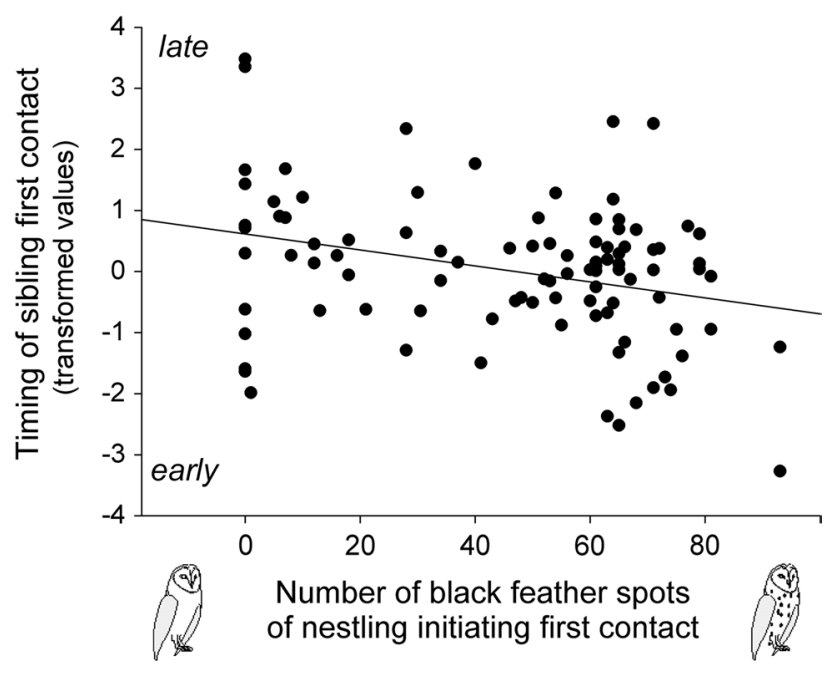

Fig. 6 Timing of first contact (min) in relation to the number of black feather spots of the initiator of the first physical contact in pairs of barn owl siblings. The timing of the first contact represents the time period between the moment the two siblings were placed in the nest-box and the first huddling. Data are from 2012

spots searched for physical contact with their sibling more often and more rapidly when temperature was low (Figs. 4, 5,6 ). Our study shows coherent patterns between social and physiological thermoregulation and a melanic trait in three different experiments using different samples of nestlings. In the following, we discuss the potential proximate mechanisms underlying these findings and their evolutionary ecology implications.

In the barn owl, we show that nestlings exposed to even moderately cool ambient temperatures (i.e. below approximately $26{ }^{\circ} \mathrm{C}$; Fig. 2) exhibit a lower body temperature, contrary to adults which maintain a constant body temperature over a large range of ambient temperatures (Thouzeau et al. 1999). This suggests that the thermoneutral zone (TNZ) may be narrower for nestlings than for adults (23-32 ${ }^{\circ} \mathrm{C}$ for adults; Edwards 1987; Thouzeau et al. 1999). Young altricial endotherms are typically less able to regulate body temperature than adults, either because they have immature feathers/fur and/or because of the trade-off between thermoregulation and other physiological processes such as growth or immunity (Burness et al. 2010; Dawson et al. 2005; Olson 1992). In addition, our results suggest that the TNZ of barn owl nestlings may vary with plumage melanism. Accordingly, resting metabolic rate was minimal for lightly spotted young at $24{ }^{\circ} \mathrm{C}$, as expected if $24{ }^{\circ} \mathrm{C}$ was within the TNZ. Conversely, RMR stayed high at all temperatures for highly spotted young.

The relationship between melanin-based coloration and huddling behaviour reported in the present study is likely to reflect melanin-specific thermoregulatory strategy. Indeed, limitation in the ability to thermoregulate is thought to partly explain the evolution of huddling behaviour (Gilbert et al. 2010). Huddling behaviour has been suggested to be a social thermoregulatory mechanism (Gilbert et al. 2010) which allows animals to save energy and lose less heat in periods of cold weather (Ancel et al. 1997; Duplessis et al. 1994; Gilbert et al. 2010; McKechnie and Lovegrove 2001; Scantlebury et al. 2006). Huddling may also have emerged because it dilutes predation risk (Gilbert et al. 2010); however, it is not the case in species in which young cannot leave their nest, such as in the barn owl studied here. Social activities such as allopreening/grooming could also induce huddling (Ancillotto et al. 2012), but allopreening was not correlated with time spent together in our study population (unpublished data).

Our results are consistent with the hypothesis that the number of eumelanic spots in nestling barn owls affects the thermoregulatory strategy. Highly spotted nestlings had higher resting metabolic rate and lower body temperature, suggesting a higher thermal conductance. As a consequence, they seemed to adjust their behaviour to ambient temperature, huddling more rapidly to their siblings. We propose that the lower body temperature of highly spotted nestlings kept in isolation is not due to a lower set point temperature (i.e. a lower temperature of comfort), but rather a lower ability to thermoregulate. Indeed, the fact that these nestlings consumed more oxygen and tended to aggregate more than other nest-mates suggest that they sought to reduce heat loss when the temperature was below $26{ }^{\circ} \mathrm{C}$. In ectotherms, melanism plays an important role to absorb solar radiation, and darker individuals are better able to maintain a high body temperature (Clusella-Trullas et al. 2008). The barn owl melanic spots themselves are unlikely to have such a thermoregulatory role, because they are small and owls are nocturnal. Moreover, under this hypothesis, we would have expected darker individuals to show a higher body temperature and we found the opposite result. The melanic spots could still be correlated with 
plumage or down density and thermal insulation (see, e.g., Koskenpato et al. 2015). We propose that genes participating in melanogenesis such as melanocortins influence energy homeostasis. Alternatively, because highly spotted nestling barn owls invest more energy in growth than lightly spotted ones (Almasi and Roulin 2015), they may be less able to thermoregulate, and, as a consequence, they adjust their behaviour to ambient temperature. Larger-spotted nestlings of either sex grow faster and are heavier than smaller-spotted nestlings (Almasi and Roulin 2015), spot size being strongly genetically correlated with spot number (Roulin and Jensen 2015).

Our results suggest that lightly spotted individuals need to invest less energy to sustain a high body temperature. Therefore, individuals displaying fewer black spots may enjoy a selective advantage when the weather is cold, a prediction that we need to address using our long-term monitoring of breeding adults (e.g. Roulin et al. 2010). Another prediction is that Tyto species/subspecies living in colder regions must display fewer black spots than those living in warmer regions. Accordingly, in the northern hemisphere, Tyto species/subspecies exhibit smaller black spots (a trait highly correlated with spot number, Roulin 2004b) at higher latitudes (Roulin et al. 2009). Furthermore, in the North American continent, barn owls display fewer black spots in colder regions (Roulin and Randin 2015).

The range of ambient temperatures for which body temperature was measured here was limited $\left(13.5-33.3{ }^{\circ} \mathrm{C}\right)$; hence, it remains unclear whether under warmer temperatures, as those experienced near the equator, barn owls displaying more black spots would have a thermoregulatory selective advantage. This would raise the possibility that current global warming selects for heavily spotted barn owls.

\section{Conclusion}

Our study shows that melanin-based coloration is correlated with thermoregulation physiology and behaviour. We suggest that genes involved in melanogenesis affect energy homeostasis, which could explain why differently coloured individuals adopt different life history strategies and exploit alternative habitats. An implication is that the need to warm up during periods of cold induces melanic individuals to aggregate with their siblings. This raises the interesting possibility that the degree of melanism may become associated with social behaviour (e.g. Roulin et al. 2012).

Acknowledgments We thank Cécile A. Dreiss, Anne-Lyse Ducrest and two anonymous referees for their constructive comments.

Author contribution statement PB conducted the field and laboratory work on body temperature, a project designed by BA, LJ and AR. RS, PB \& MG designed the oxygen consumption experiment and
RS conducted this experiment and analysed the data. NV analysed the social thermoregulation videos, a project designed by $\mathrm{AD}$. AD and AR supervised the project and wrote the manuscript.

\section{References}

Almasi B, Roulin A (2015) Signalling value of maternal and paternal melanism in the barn owl: implication for the resolution of the lek paradox. Biol J Linn Soc 115:376-390. doi:10.1111/ bij. 12508

Almasi B, Roulin A, Jenni L (2013) Corticosterone shifts reproductive behaviour towards self-maintenance in the barn owl and is linked to melanin-based coloration in females. Horm Behav 64:161-171. doi:10.1016/j.yhbeh.2013.03.001

Ancel A, Visser H, Handrich Y, Masman D, LeMaho Y (1997) Energy saving in huddling penguins. Nature 385:304-305. doi: $10.1038 / 385304 \mathrm{a} 0$

Ancillotto L, Serangeli MT, Russo D (2012) Spatial proximity between newborns influences the development of social relationships in bats. Ethology 118:331-340. doi:10.1111/j.1439-0310.2011.02016.x

Angilletta MJ, Niewiarowski PH, Navas CA (2002) The evolution of thermal physiology in ectotherms. J Therm Biol 27:249-268. doi:10.1016/s0306-4565(01)00094-8

Angilletta MJ, Cooper BS, Schuler MS, Boyles JG (2010) The evolution of thermal physiology in endotherms. Front Biosci E2:861-881

Burness G, Armstrong C, Fee T, Tilman-Schindel E (2010) Is there an energetic-based trade-off between thermoregulation and the acute phase response in zebra finches? J Exp Biol 213:13861394. doi: $10.1242 /$ jeb. 027011

Caro T (2013) The colours of extant mammals. Semin Cell Dev Biol 24:542-552. doi:10.1016/j.semcdb.2013.03.016

Challis BG et al (2004) Mice lacking pro-opiomelanocortin are sensitive to high-fat feeding but respond normally to the acute anorectic effects of peptide-YY3-36. Proc Natl Acad Sci USA 101:4695-4700. doi:10.1073/pnas.0306931

Clusella-Trullas S, Terblanche JS, Blackburn TM, Chown SL (2008) Testing the thermal melanism hypothesis: a macrophysiological approach. Funct Ecol 22:232-238. doi:10.1111/j.1365-2435.2007.01377.x

Crompton AW, Taylor CR, Jagger JA (1978) Evolution of homeothermy in mammals. Nature 272:333-336. doi:10.1038/272333a0

Dawson RD, Lawrie CC, O'Brien EL (2005) The importance of microclimate variation in determining size, growth and survival of avian offspring: experimental evidence from a cavity nesting passerine. Oecologia 144:499-507. doi:10.1007/ s00442-005-0075-7

Dikmen S, Cole JB, Null DJ, Hansen PJ (2012) Heritability of rectal temperature and genetic correlations with production and reproduction traits in dairy cattle. J Dairy Sci 95:3401-3405. doi:10.3168/jds.2011-4306

Dreiss AN, Roulin A (2010) Age-related change in melaninbased coloration of Barn owls (Tyto alba): females that become more female-like and males that become more male-like perform better. Biol J Linn Soc 101:689-704. doi:10.1111/j.1095-8312.2010.01503.x

Dreiss AN, Henry I, Ruppli CA, Almasi B, Roulin A (2010) Darker eumelanic barn owls better withstand food depletion through resistance to food deprivation and lower appetite. Oecologia 164:65-71. doi:10.1007/s00442-010-1680-7

Dreiss AN et al (2012) Local adaptation and matching habitat choice in female barn owls with respect to melanic coloration. J Evol Biol 25:103-114. doi:10.1111/j.1420-9101.2011.02407.x 
Dreiss AN, Ruppli CA, Oberli F, Antoniazza S, Henry I, Roulin A (2013) Barn owls do not interrupt their siblings. Anim Behav 86:119-126. doi:10.1016/j.anbehav.2013.04.019

Ducrest AL, Keller L, Roulin A (2008) Pleiotropy in the melanocortin system, coloration and behavioural syndromes. Trends Ecol Evol 23:502-510. doi:10.1016/j.tree.2008.06.001

Dunn EH (1975) Timing of endothermy in development of altricial birds. Condor 77:288-293. doi:10.2307/1366224

Duplessis MA, Weathers WW, Koenig WD (1994) Energetic benefits of communal roosting by acorn woodpeckers during the nonbreeding season. Condor 96:631-637. doi:10.2307/1369466

Durant JM (2002) The influence of hatching order on the thermoregulatory behaviour of barn owl Tyto alba nestlings. Avian Sci 2:167-173

Edwards TC (1987) Standard rate of metabolism in the common barn owl (Tyto alba). Wilson Bull 99:704-706

Else PL, Hulbert AJ (1981) Comparison of the mammal machine and the reptile machine-energy production. Am J Physiol 240:R3-R9

Forbes S (2002) Sibling symbiosis in nestling birds. Auk 124:1-10. doi:10.1642/0004-8038(2007)124[1:SSINB]2.0.CO;2

Galeotti P, Rubolini D, Sacchi R, Fasola M (2009) Global changes and animal phenotypic responses: melanin-based plumage redness of scops owls increased with temperature and rainfall during the last century. Biol Lett 5:532-534. doi:10.1098/rsbl.2009.0207

Gilbert $\mathrm{C}$ et al (2010) One for all and all for one: the energetic benefits of huddling in endotherms. Biol Rev 85:545-569. doi:10.1111/j.1469-185X.2009.00115.x

Hegna RH, Nokelainen O, Hegna JR, Mappes J (2013) To quiver or to shiver: increased melanization benefits thermoregulation, but reduces warning signal efficacy in the wood tiger moth. Proc R Soc Lond B. doi:10.1098/rspb.2012.2812

Heppner F (1970) The metabolic significance of differential absorption of radiant energy by black and white birds. Condor 72:50-59

Hetem RS et al (2009) Body temperature, thermoregulatory behaviour and pelt characteristics of three colour morphs of springbok (Antidorcas marsupialis). Comp Biochem Physiol A 152:379_ 388. doi:10.1016/j.cbpa.2008.11.011

Hudson R, Bautista A, Reyes-Meza V, Montor JM, Rodel HG (2011) The effect of siblings on early development: a potential contributor to personality differences in mammals. Dev Psychobiol 53:564-574. doi:10.1002/dev.20535

Irving L, Krog J (1954) Body temperatures of arctic and subarctic birds and mammals. J Appl Physiol 6:667-680

Järvistö PE, Calhim S, Schuett W, Velmala W, Laaksonen T (2015) Foster, but not genetic, father plumage coloration has a temperature-dependent effect on offspring quality. Behav Ecol Sociobiol 69:335-346. doi:10.1007/s00265-014-1846-0

Jones KMM, Boulding EG (1999) State-dependent habitat selection by an intertidal snail: the costs of selecting a physically stressful microhabitat. J Exp Mar Biol Ecol 242:149-177. doi:10.1016/ S0022-0981(99)00090-8

Karell P, Ahola K, Karstinen T, Valkama J, Brommer JE (2011) Climate change drives microevolution in a wild bird. Nat Commun 2:208. doi:10.1038/ncomms 1213

Karpestam E, Wennersten L, Forsman A (2012) Matching habitat choice by experimentally mismatched phenotypes. Evol Ecol 26:893-907. doi:10.1007/s10682-011-9530-6

Kearney M, Shine R, Porter WP (2009) The potential for behavioral thermoregulation to buffer "cold-blooded" animals against climate warming. Proc Natl Acad Sci USA 106:3835-3840. doi:10.1073/pnas.0808913106

Kittilsen S et al (2009) Melanin-based skin spots reflect stress responsiveness in salmonid fish. Horm Behav 56:292-298. doi:10.1016/j.yhbeh.2009.06.006
Koskenpato K, Ahola K, Karstinen T, Karell P (2015) Is the denser contour feather structure in pale grey than in pheomelanic brown tawny owls (Strix aluco) an adaptation to cold environments? J Avian Biol. doi:10.1111/jav.00746

Lichtenbelt WDV, Westerterp-Plantenga MS, van Hoydonck P (2001) Individual variation in the relation between body temperature and energy expenditure in response to elevated ambient temperature. Physiol Behav 73:235-242

Lichtenbelt WDV, Schrauwen P, Van De Kerckhove SV, Westerterp-Plantenga MS (2002) Individual variation in body temperature and energy expenditure in response to mild cold. Am J Physiol Endocrinol Metab 282:E1077-E1083. doi:10.1152/ ajpendo.00020.2001

Lute B et al (2014) Biphasic effect of melanocortin agonists on metabolic rate and body temperature. Cell Metab 20:333-345. doi:10.1016/j.cmet.2014.05.021

McKechnie AE, Lovegrove BG (2001) Thermoregulation and the energetic significance of clustering behavior in the white-backed mousebird (Colius colius). Physiol Biochem Zool 74:238-249. doi: $10.1086 / 319669$

McNab BK (1997) On the utility of uniformity in the definition of basal rate of metabolism. Physiol Zool 70:718-720

Mosher JA, Henny CJ (1976) Thermal adaptiveness of plumage color in screech owls. Auk 93:614-619

Muri D et al (2015) Thermoregulation and microhabitat choice in the polymorphic asp viper (Vipera aspis). J Therm Biol 53:107-112. doi:10.1016/j.jtherbio.2015.06.009

Nespolo RF, Bacigalupe LD, Bozinovic F (2003) Heritability of energetics in a wild mammal, the leaf-eared mouse (Phyllotis darwini). Evolution 57:1679-1688

Olson JM (1992) Growth, the development of endothermy, and the allocation of energy in red-winged blackbirds (Agelaius phoeniceus) during the nestling period. Physiol Zool 65:124-152

Parkash R, Sharma V, Kalra B (2010) Correlated changes in thermotolerance traits and body color phenotypes in montane populations of Drosophila melanogaster: analysis of within- and between-population variations. J Zool 280:49-59. doi:10.1111/j.1469-7998.2009.00641.x

Py I, Ducrest AL, Duvoisin N, Fumagalli L, Roulin A (2006) Ultraviolet reflectance in a melanin-based plumage trait is heritable. Evol Ecol Res 8:483-491

Reyes-Meza V, Hudson R, Martinez-Gomez M, Nicolas L, Rodel HG, Bautista A (2011) Possible contribution of position in the litter huddle to long-term differences in behavioral style in the domestic rabbit. Physiol Behav 104:778-785. doi:10.1016/j. physbeh.2011.07.019

Roulin A (2004a) Effects of hatching asynchrony on sibling negotiation, begging, jostling for position and within-brood food allocation in the barn owl, Tyto alba. Evol Ecol Res 6:1083-1098

Roulin A (2004b) Proximate basis of the covariation between a melanin-based female ornament and offspring quality. Oecologia 140:668-675. doi:10.1007/s00442-004-1636-x

Roulin A, Ducrest AL (2011) Association between melanism, physiology and behaviour: a role for the melanocortin system. Eur J Pharmacol 660:226-233

Roulin A, Jensen H (2015) Sex-linked inheritance, genetic correlations and sexual dimorphism in three melanin-based color traits in the barn owl. J Evol Biol 28:655-666. doi:10.1111/jeb.12596

Roulin A, Randin C (2015) Gloger's rule in North American barn owls. Auk 132:321-332. doi:10.1642/AUK-14-167.1

Roulin A, Kolliker M, Richner H (2000) Barn owl (Tyto alba) siblings vocally negotiate resources. Proc R Soc Lond B 267:459-463. doi:10.1098/rspb.2000.1022

Roulin A, Bize P, Tzaud N, Bianchi M, Ravussin P-A, Christe P (2005) Oxygen consumption in offspring tawny owls Strix aluco 
is associated with colour morph of foster mother. J Ornithol 146:390-394. doi:10.1007/s10336-005-0096-3

Roulin A et al (2008) Corticosterone mediates the condition-dependent component of melanin-based coloration. Anim Behav 75:1351-1358. doi:10.1016/j.anbehav.2007.09.007

Roulin A, Wink M, Salamin N (2009) Selection on a eumelanic ornament is stronger in the tropics than in temperate zones in the worldwide-distributed barn owl. J Evol Biol 22:345-354. doi:10.1111/j.1420-9101.2008.01651.x

Roulin A, Altwegg R, Jensen H, Steinsland I, Schaub M (2010) Sexdependent selection on an autosomal melanic female ornament promotes the evolution of sex ratio bias. Ecol Lett 13:616-626. doi:10.1111/j.1461-0248.2010.01459.x

Roulin A, Da Silva A, Ruppli CA (2012) Dominant nestlings displaying female-like melanin coloration behave altruistically in the barn owl. Anim Behav 84:1229-1236. doi:10.1016/j. anbehav.2012.08.033

Roulin A, Mangels J, Wakamatsu K, Bachmann T (2013) Sexually dimorphic melanin-based colour polymorphism, feather melanin content, and wing feather structure in the barn owl (Tyto alba). Biol J Linn Soc 109:562-573. doi:10.1111/bij.12078

Scantlebury M, Bennett NC, Speakman JR, Pillay N, Schradin C (2006) Huddling in groups leads to daily energy savings in free-living African four-striped grass mice, Rhabdomys pumilio. Funct Ecol 20:166-173. doi:10.1111/j.1365-2435.2006.01074.x

Schmidt-Nielsen K (1997) Animal physiology. Adaptation and environment, 5th edn. Cambridge University Press, Cambridge
Sinha PS, Schioth HB, Tatro JB (2004) Roles of the melanocortin-4 receptor in antipyretic and hyperthermic actions of centrally administered alpha-MSH. Brain Res 1001:150-158. doi:10.1016/j.brainres.2003.12.007

Sirkiä PM, Virolainen M, Laaksonen T (2010) Melanin coloration has temperature-dependent effects on breeding performance that may maintain phenotypic variation in a passerine bird. J Evol Biol 23:2385-2396. doi:10.1111/j.1420-9101.2010.02100.x

Sirkiä PM, Virolainen M, Lehikoinen M, Laaksonen T (2013) Fluctuating selection and immigration as determinants of the phenotypic composition of a population. Oecologia 173:305-317. doi:10.1007/s00442-013-2593-z

Tanaka K (2007) Thermal biology of a colour-dimorphic snake, Elaphe quadrivirgata, in a montane forest: do melanistic snakes enjoy thermal advantages? Biol J Linn Soc 92:309-322. doi:10.1111/j.1095-8312.2007.00849.x

Thouzeau C, Duchamp C, Handrich Y (1999) Energy metabolism and body temperature of barn owls fasting in the cold. Physiol Biochem Zool 72:170-178. doi:10.1086/316659

Walsberg GE (1991) Thermal effects of seasonal coat change in 3 sub-arctic mammals. J Therm Biol 16:291-296. doi:10.1016/0306-4565(91)90020-3

Walsberg GE, Campbell GS, King JR (1978) Animal coat color and radiative heat gain: re-evaluation. J Comp Physiol 126:211-222

Willis CKR, Brigham RM (2007) Social thermoregulation exerts more influence than microclimate on forest roost preferences by a cavity-dwelling bat. Behav Ecol Sociobiol 62:97-108. doi:10.1007/s00265-007-0442-y 